\title{
ELABORACIÓN DE ENSILADO BIOLÓGICO A PARTIR DE RESIDUO CRUDO DE TRUCHA ARCO IRIS (Oncorhynchus mykiss (Walbaum, 1792)) EN PUNO, PERÚ
}

\section{ELABORATION OF BIOLOGICAL SILAGE FROM RAW RAINBOW TROUT (Oncorhynchus mykiss (Walbaum, 1792)) WASTES IN PUNO, PERU}

\author{
Maritza Barriga-Sánchez ${ }^{1}$, Marisol Churacutipa ${ }^{2}$ y Alberto Salas ${ }^{3}$
}

\section{Resumen}

El objetivo de este trabajo fue elaborar ensilado biológico utilizando residuos crudos de trucha (Oncorhynchus mykiss (Walbaum, 1792)) en las condiciones ambientales de Puno, Perú, utilizando koji como cultivo de Aspergillus oryzae. Primero, las condiciones de incubación óptimas para A. oryzae se determinaron utilizando dos fuentes de carbohidratos de la zona: papa y cebada; también se utilizó arroz, a las temperaturas y tiempos sugeridos por el diseño estadístico del método de superficie de respuesta. La variable de respuesta fue el conteo de mohos en unidades formadoras de colonia por gramo (UFC/g). Luego, se plantearon tratamientos con los inóculos de koji a temperaturas y tiempos óptimos, con melaza y residuos triturados crudos de trucha. Se realizaron las mediciones de $\mathrm{pH}$, acidez, histamina y olor de cada uno de los tratamientos de ensilado. Los resultados fueron: temperaturas y tiempos óptimos de incubación de $A$. oryzae a $25^{\circ} \mathrm{C}$ y 60 horas en cebada, $26{ }^{\circ} \mathrm{C}$ y 62 horas en papa, $25{ }^{\circ} \mathrm{C}$ y 60 horas en arroz. El mejor tratamiento de ensilado fue el que tenía la proporción de residuo crudo de trucha : melazam : koji en arroz de $10: 1.5: 1$, pH de 4.5 , puntaje de "5" en el olor, y menores valores de histamina $(83.7 \mathrm{mg} / \mathrm{kg})$ hasta los 90 días de almacenamiento a temperatura ambiente. Este trabajo brinda una alternativa de uso de los residuos de la industria truchícola para la elaboración de ensilado biológico como insumo de alimento para cerdos y ovejas, contribuyendo a disminuir la contaminación ambiental orgánica en Puno, Perú.

Palabras clave: ensilado biológico, residuos crudos de trucha, Arapa, Puno.

\begin{abstract}
The objective of this work was to elaborate biological silage using raw trout (Oncorhynchus mykiss (Walbaum, 1792)) wastes under Puno's environmental conditions; using koji as a culture of Aspergillus oryzae. First, optimal incubation conditions for A. oryzae (koji) were determined using two local carbohydrate sources: potato and barley as well as rice, under temperatures and times suggested by the experimental statistical design of the surface response method. The response variable was the counting of molds as colony forming units per gram (CFU/g). Next different treatments were postulated with koji inocula under optimal temperatures and times with ground raw trout waste and molasses. $\mathrm{pH}$, acidity, histamine and odor measurements of each treatments were carried out. The results were: temperature and optimum incubation time of $A$. oryzae at $25^{\circ} \mathrm{C}$ and 60 hours in barley, $26^{\circ} \mathrm{C}$ and 62 hours in potatoes, $25^{\circ} \mathrm{C}$ and $60 \mathrm{hrs}$ in rice. The best treatment was the one with the proportion of raw waste of trout : molasses : koji in rice $(10: 1.5: 1), \mathrm{pH}$ of 4.5 , the score of " 5 " for odor, and lower values of histamine $(83.7 \mathrm{mg} / \mathrm{kg})$ up to 90 days of storage at room temperature. This work offers an alternative for the use of trout wastes in the elaboration of biological silage for swine and sheep feed. It also contributes to the decreasing of organic environmental pollution in Puno, Peru.
\end{abstract}

Key words: biological silage, raw waste of trout, Arapa, Puno.

\section{Introducción}

En nuestro país, el cultivo de trucha arco iris (Oncorhynchus mykiss (Walbaum, 1792)), trucha en lo sucesivo, ha presentado un crecimiento en los últimos años, alcanzando en el 2015, en Puno, la mayor extracción, llegando a $34207.22 \mathrm{t}$, correspondiendo al $82.9 \%$ de la extracción a nivel nacional (Ministerio de la Producción - Perú, 2015). Se estima que los residuos de trucha (vísceras, cabeza, aletas, espina dorsal) generados en Puno por la comercialización de la trucha fresca eviscerada, deshuesada o en filetes fueron de 15 $000 \mathrm{t}$ al año, lo cual representa un problema de contaminación por materia orgánica en las fuentes de agua u otros ecosistemas, debido a que generalmente 
colocan los residuos de la trucha en fosas, cerca de los lagos o lagunas y por efecto de la lluvia y condiciones del suelo, los residuos resultan en el lago o laguna. En ese sentido, la propuesta de solución es la elaboración de ensilado. En este trabajo se presenta una alternativa tecnológica simple, de baja inversión y que no requiere de equipos costosos, ni mano de obra calificada.

En el proceso de ensilado biológico se obtiene un producto líquido-pastoso acidificado estable con alto valor biológico, que puede ser empleado como insumo en la preparación de dietas para alimentación animal. Existen diversos tipos de ensilaje de pescado o de sus residuos, biológicos o químicos. En los ensilados biológicos participan microorganismos, mientras que los ensilados químicos usan ácidos orgánicos (fórmico, propiónico) o inorgánicos (sulfúrico y clorhídrico), llegando rápidamente a $\mathrm{pH}$ de 3.8 a 4.0 (Herrampf \& Piedad-Pascual, 2000). En 1990, el Instituto Tecnológico Pesquero del Perú desarrolló una técnica de obtención de ensilado biológico a partir de residuos cocidos de pescado de origen marino utilizando bacterias lácticas, el ensilado fue empleado como insumo para la alimentación de pollos y cerdos (Areche \& Berenz, 1990; Berenz et al., 1994).

El proceso necesitaba consumo de energía para la cocción de residuos y la incubación durante 48 horas a $40{ }^{\circ} \mathrm{C}$, condiciones necesarias para el crecimiento de las bacterias lácticas. Con el propósito de disminuir los costos de producción, Albrecht \& Torpoco (2008) usaron koji (insumo alimentario requerido para el proceso de fermentación de la salsa de soja para consumo humano) y prepararon ensilado mezclando residuos crudos de pescado, melaza y koji (soja inoculada con cepas de Aspergillus oryzae, Zigosaccharoomyces rouxii y Tetragenococcus halophylus) en la proporción de $9: 1$ : 1 , respectivamente, a $37{ }^{\circ} \mathrm{C}$ de incubación, logrando alcanzar valores de $\mathrm{pH}<4.5$ y vida útil de 30 días. Posteriormente, se realizaron pruebas a mayor escala (nivel piloto) utilizando koji y residuo crudo de anchoveta, melaza y koji (soja inoculada con cepas de A. oryzae) en la proporción de $10: 1.5: 1$, respectivamente. Un grupo de muestras de ensilado fue almacenado a temperatura ambiente y otro grupo en incubación a $40{ }^{\circ} \mathrm{C}$ por 96 horas. Solo el grupo que fue llevado a $40{ }^{\circ} \mathrm{C}$ mantuvo el $\mathrm{pH}<4.5$ hasta 90 días (Albrecht \& Salas, 2013).

Este trabajo brinda una técnica de elaboración de ensilado de baja demanda de energía, no requiere cocción del residuo y en reemplazo de las bacterias lácticas se empleó koji (Aspergillus oryzae). Tampoco se requiere incubación para el proceso de ensilado, siendo una alternativa de uso de los residuos de trucha para contribuir a la disminución de la contaminación ambiental en Puno. Es la primera investigación de este tipo usando otros microorganismos en los residuos crudos de trucha a las condiciones ambientales de Puno.
El objetivo planteado fue elaborar ensilado biológico a las condiciones ambientales de Puno, utilizando los residuos crudos de trucha arco iris (Oncorhynchus mykiss (Walbaum, 1792)), melaza y koji como fuente de microorganismos que disminuirán el $\mathrm{pH}$ de los residuos.

\section{Materiales y métodos}

Las pruebas experimentales de elaboración de ensilado fueron desarrolladas en la comunidad campesina Iscayapi, cerca del Lago de Arapa, provincia de Azángaro, Región Puno. Coordenadas 15¹0'59”S $69^{\circ} 58^{\prime} 10^{\prime \prime}$.

Se utilizaron dos etapas, en la primera etapa, con la finalidad de encontrar las temperaturas y tiempos óptimos para el mayor crecimiento de Aspergillus oryzae, se realizaron siembras del hongo en tres sustratos: arroz, papa blanca y cebada, según lo sugerido por el método de superficie de respuesta.

En la segunda etapa con el objetivo de encontrar una formulación de ensilado que no requiera cocción de residuos ni incubación en el proceso de ensilado, se elaboraron ensilados usando el koji de papa, cebada y arroz, cultivados a temperaturas y tiempos óptimos determinados en la primera etapa. Se evaluaron en cada uno de ellos los parámetros de $\mathrm{pH}$, acidez, olor y se determinó los $\mathrm{mg} / \mathrm{kg}$ de histamina. Se consideró como la mejor formulación aquella que registró un $\mathrm{pH} \leq 4.5$ hasta los 90 días de almacenamiento, con olor aceptable y valores de histamina $<200 \mathrm{mg} / \mathrm{kg}$.

\section{Preparación de koji}

El koji es una mezcla de soja cocida y trigo, con Aspergillus oryzae, con límite de mohos de $10^{6} \mathrm{UFC} / \mathrm{g}$; levaduras $10^{3} \mathrm{UFC} / \mathrm{g}$ y bacterias mesófilas aerobias $10^{3}$ UFC/g (Ficha técnica de Kikko).

En recipientes separados se llevaron a ebullición, durante 10 minutos: el arroz (sin lavar), papa (lavada, cortadas en rodajas) y cebada sin tostar (lavada). Se retiró el agua al arroz, la papa y cebada, y se dejó enfriar a temperatura ambiente. Luego se agregó koji Kikko ® a cada recipiente, se mezcló y se llevaron a incubación, a la temperatura y tiempo indicados en el Tabla 1.

Transcurrido el tiempo de incubación, se determinó el conteo de hongos y los resultados fueron ingresados en el programa Meet Minitab versión 15 (Minitab) (Minitab, 2007). También se determinó la temperatura y tiempo óptimos de crecimiento de A. oryzae en arroz, papa y cebada.

Estas pruebas fueron realizadas en las instalaciones del laboratorio de microbiología del Instituto Tecnológico de la Producción (ITP).

En el laboratorio de Iscayapi (Arapa/Puno), se preparó el koji de papa, cebada y arroz, a la temperatura y tiempo óptimos. Se usó una incubadora Memmert de 74 litros. Después de obtener el crecimiento de $A$. oryzae, se utilizó para la elaboración del ensilado. 


\section{Análisis microbiológicos}

La determinación de mohos se realizó en el laboratorio LABS-ITP, acreditado según la ISO-IEC 17025:2005. Se siguió el método de Numeración de Mohos y Levaduras (FDA, 2001). Este ensayo fue realizado al koji con papa, con cebada, con arroz, la melaza y el ensilado.

Así mismo, se determinó la numeración de microorganismos aerobios mesófilos (FDA, 2001), en la melaza, residuo crudo de trucha y ensilados.

Análisis químicos

Se determinó la cantidad de proteína, grasa, ceniza y humedad según la FAO (1986); el pH por lectura directa, con un electrodo BlueLine 21PHmarca Schott para muestras semisólidas acoplado a un potenciómetro marca Schott de Alemania. Se emplearon soluciones buffer de calibración de pH 4.0, 7.0 y 9.0, trazables a Nist. Para la determinación del porcentaje de acidez (\%), se siguió el método AOAC 947.05, (AOAC, 2005) expresado en ácido láctico; la histamina se determinó según el método de la Norma Chilena Oficial NCh2637.Of.2001 (Instituto Nacional de Normalización - Chile, 2001), utilizando un HPLC (cromatógrafo líquido) marca Perkin Elmer series 200, con detector UV. Para la curva de calibración se usó como estándar diclorhidrato de histamina de la marca Sigma. Los análisis se realizaron por duplicado para cada muestra.

Análisis sensorial

Las características del atributo olor fueron evaluadas con una ficha sensorial de 5 puntos, elaborada previamente con pruebas preliminares para este estudio:

5.- Olor a pescado y moderado a frutas fermentadas;

4.- Olor a pescado y leve a frutas fermentadas;

3.- Olor a pescado y melaza;

2.- Olor de pescado con indicios de descomposición, azufrado, rancio;

1.- Pescado pútrido.

Calificaciones mayores o iguales a 3 son aceptables, la calificación inicial de los ensilados correspondía a 3 puntos.

Análisis estadístico

Las condiciones óptimas de incubación para los diferentes sustratos fueron determinadas con la metodología de superficie de respuesta (MSR) con diseño compuesto central rotable. Se utilizó el programa estadístico Minitab; el diseño consideró 5 niveles para cada factor (Tabla 1), para la cebada, papa y arroz, los niveles están con códigos: $-2,-1,0,1$ y 2 . El programa Minitab diseñó 10 experimentos según los niveles con una repetición en el nivel central (Tabla 2). El nivel superior de la temperatura de incubación (45 ${ }^{\circ} \mathrm{C}$ ) de la papa se disminuyó, debido a que en los minutos de incubación el sustrato se licuefactó, considerándose valores diferentes que los niveles de cebada.
Se utilizó el programa SPSS versión 19 para los análisis de regresión y de varianza de la variable dependiente histamina con 2 factores: tiempo y tratamiento. Se aplicó el ANOVA de 1 factor y la prueba de Duncan para comparar la formación de histamina entre los tratamientos de ensilado, a un nivel de confianza $\alpha=0.05$.

Tabla 1. Niveles de las variables independientes temperatura $(\mathrm{T})$ y tiempo $(\mathrm{t})$ sugeridos por el diseño compuesto central para la optimización del crecimiento de Aspergillus oryzae en cebada, papa y arroz.

\begin{tabular}{lllllll}
\hline & Variables & \multicolumn{2}{c}{ Niveles } & & & \\
& & -2 & -1 & 0 & 1 & 2 \\
\hline Cebada & $\mathrm{T}\left({ }^{\circ} \mathrm{C}\right)$ & 25 & 30 & 35 & 40 & 45 \\
& $\mathrm{t}(\mathrm{h})$ & 12 & 24 & 36 & 48 & 60 \\
Papa & $\mathrm{T}\left({ }^{\circ} \mathrm{C}\right)$ & 20 & 25 & 30 & 35 & 40 \\
& $\mathrm{t}(\mathrm{h})$ & 24 & 36 & 48 & 60 & 70 \\
Arroz & $\mathrm{T}\left({ }^{\circ} \mathrm{C}\right)$ & 20 & 25 & 30 & 35 & 40 \\
& $\mathrm{~T}(\mathrm{~h})$ & 12 & 24 & 36 & 48 & 60 \\
\hline
\end{tabular}

Tabla 2. Experimentos sugeridos por el software Meet Minitab versión 15.

\begin{tabular}{|c|c|c|c|c|c|c|c|c|}
\hline \multicolumn{2}{|l|}{ Niveles } & \multicolumn{3}{|c|}{ Cebada } & \multirow{2}{*}{$\begin{array}{c}\text { Papa } \\
\mathrm{T} \\
\left({ }^{\circ} \mathrm{C}\right)\end{array}$} & \multicolumn{3}{|c|}{ Arroz } \\
\hline Exp & $\begin{array}{c}\text { A } \\
(\mathrm{T})\end{array}$ & $\begin{array}{l}B \\
(t)\end{array}$ & $\begin{array}{c}\mathrm{T} \\
\left({ }^{\circ} \mathrm{C}\right)\end{array}$ & $\begin{array}{c}\mathrm{t} \\
(\mathrm{h})\end{array}$ & & $\begin{array}{c}\mathrm{t} \\
\text { (h) }\end{array}$ & $\begin{array}{c}\mathrm{T} \\
\left({ }^{\circ} \mathrm{C}\right)\end{array}$ & $\begin{array}{c}\mathrm{t} \\
(\mathrm{h})\end{array}$ \\
\hline 1 & -1 & -1 & 30 & 24 & 25 & 36 & 25 & 24 \\
\hline 2 & 1 & -1 & 40 & 24 & 35 & 36 & 35 & 24 \\
\hline 3 & -1 & 1 & 30 & 48 & 25 & 60 & 25 & 48 \\
\hline 4 & 1 & 1 & 40 & 48 & 35 & 60 & 35 & 48 \\
\hline 5 & -2 & 0 & 25 & 36 & 20 & 48 & 20 & 36 \\
\hline 6 & 2 & 0 & 45 & 36 & 40 & 48 & 40 & 36 \\
\hline 7 & 0 & -2 & 35 & 12 & 30 & 24 & 30 & 12 \\
\hline 8 & 0 & 2 & 35 & 60 & 30 & 72 & 30 & 60 \\
\hline 9 & 0 & 0 & 35 & 36 & 30 & 48 & 30 & 36 \\
\hline 10 & 0 & 0 & 35 & 36 & 30 & 48 & 30 & 36 \\
\hline
\end{tabular}

\section{$\underline{\text { Preparación del ensilado }}$}

\section{Insumos}

Residuos generados del procesamiento de filete de trucha de la empresa Arapa San Pedro y San Pablo S.A.C., que constan de cabeza, aletas, espina dorsal y vísceras. Se usó melaza con $0.74 \% \pm 0.4$ de nitrógeno, humedad 29.8\% \pm 0.1 ; cenizas $11.3 \% \pm 0.1$, pH 5.45; $73.5^{\circ}$ Brix.

Koji en arroz, en papa blanca y en cebada; incubados a la temperatura y tiempo optimizados.

\section{Preparación}

Se trituraron los residuos con una moledora de carne Ferton- MLCO32 con capacidad de $320 \mathrm{~kg} / \mathrm{h}$ y con la melaza fueron colocados en baldes de 10 litros, se mezclaron y luego se agregó el koji según las cantidades establecidas en el Tabla 3. 
Los baldes cerrados fueron colocados bajo el sol desde las $11 \mathrm{~h}$ hasta las $16 \mathrm{~h}$, periodo en el cual se registraban las mayores temperaturas $\left(20\right.$ a $\left.26{ }^{\circ} \mathrm{C}\right)$, luego se guardaron los baldes en el almacén a temperatura ambiente. Los días siguientes se repetía la misma operación, hasta que el ensilado alcance $\mathrm{pH} \leq$ 4.5. Después de ello fue colocado en el almacén a temperatura ambiente, el rango de temperatura fue de 2 a $15^{\circ} \mathrm{C}$. Cada tratamiento fue realizado por triplicado.

Tabla 3. Formulaciones de los tratamientos de ensilados desarrollados en Iscayapi (Arapa/Puno).

\begin{tabular}{cccr}
\hline Tratamiento & $\begin{array}{l}\text { Residuo } \\
\text { molido } \\
(\mathrm{kg})\end{array}$ & $\begin{array}{l}\text { Melaza } \\
(\mathrm{kg})\end{array}$ & Inóculo (kg) \\
\hline $\mathrm{T} 1$ & 6 & 0.900 & $\begin{array}{r}0.600 \\
\text { koji de papa } \\
0.600\end{array}$ \\
$\mathrm{~T} 2$ & 6 & 0.900 & $\begin{array}{r}\text { koji de arroz } \\
1.100\end{array}$ \\
$\mathrm{~T} 3$ & 6 & 0.400 & $\begin{array}{r}\text { koji de arroz } \\
0.600\end{array}$ \\
$\mathrm{~T} 4$ & 6 & 0.900 & $\begin{array}{r}\text { koji de cebada } \\
\hline\end{array}$
\end{tabular}

\section{Resultados y discusión}

Optimización de la temperatura y tiempo de incubación del hongo (Aspergillus oryzae)

El análisis estadístico del conteo de UFC/g (Tabla 4) indica que el tiempo de incubación tiene un efecto significativo positivo en su crecimiento. La temperatura no tiene un efecto significativo en el conteo de las UFC/g (Figuras 1 y 2), no obstante, los valores de temperatura y tiempo fueron cercanos al rango de temperatura de $28-32{ }^{\circ} \mathrm{C}$ y el tiempo de 46 $58 \mathrm{~h}$ mencionado por Bechman et al. (2012) en los cuales $A$. oryzae tiene el mayor crecimiento y actividad $\alpha$-amilasa. Esta actividad enzimática permite en el proceso de ensilado la formación de ácidos y la disminución del $\mathrm{pH}$.

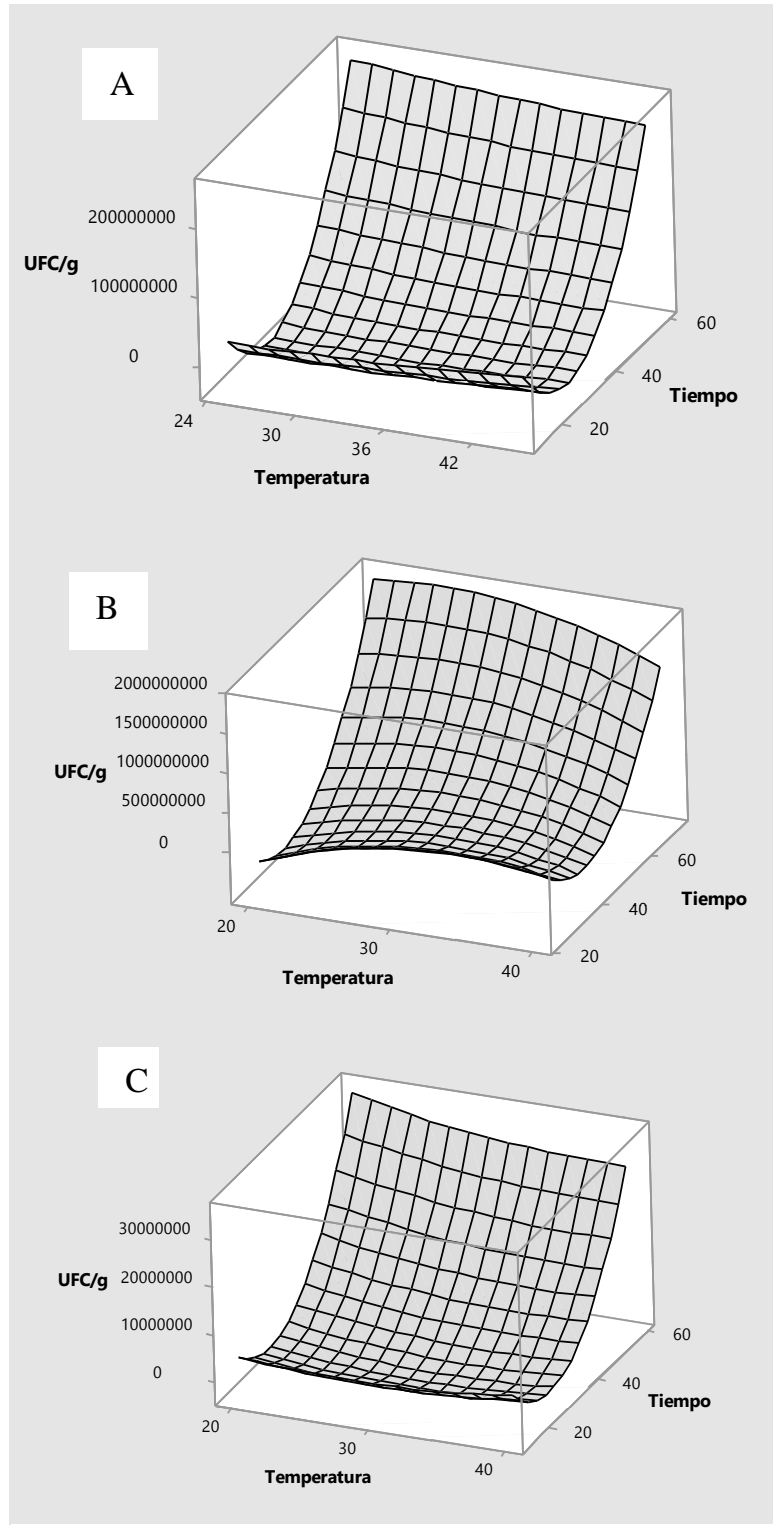

Figura 1. Superficie de respuesta del conteo de UFC/g de hongos en función a la temperatura $\left({ }^{\circ} \mathrm{C}\right)$ y el tiempo (días) de incubación. A: Cebada, B: Papa, C: Arroz.

Tabla 4. Determinación de UFC/g en cebada, papa y arroz.

\begin{tabular}{|c|c|c|c|c|c|c|c|c|}
\hline \multirow{2}{*}{$\begin{array}{l}\text { Cebada } \\
\mathrm{T}\left({ }^{\circ} \mathrm{C}\right)\end{array}$} & \multirow[b]{2}{*}{$\mathrm{t}(\mathrm{h})$} & \multicolumn{3}{|c|}{ Papa } & \multirow[b]{2}{*}{$\mathrm{UFC} / \mathrm{g}$} & \multicolumn{2}{|l|}{ Arroz } & \multirow[b]{2}{*}{$\mathrm{UFC} / \mathrm{g}$} \\
\hline & & $\mathrm{UFC} / \mathrm{g}$ & $\mathrm{T}\left({ }^{\circ} \mathrm{C}\right)$ & $\mathrm{t}(\mathrm{h})$ & & $\mathrm{T}\left({ }^{\circ} \mathrm{C}\right)$ & $\mathrm{t}(\mathrm{h})$ & \\
\hline 30 & 24 & 400000 & 25 & 36 & 2500000 & 25 & 24 & 2100000 \\
\hline 40 & 24 & 400000 & 35 & 36 & 3000000 & 35 & 24 & 880000 \\
\hline 30 & 48 & 18000000 & 25 & 60 & 250000000 & 25 & 48 & 61000000 \\
\hline 40 & 48 & 7000000 & 35 & 60 & 225000000 & 35 & 48 & 42000000 \\
\hline 25 & 36 & 1000000 & 20 & 48 & 20000000 & 20 & 36 & 44000000 \\
\hline 45 & 36 & 10000 & 40 & 48 & 14000000 & 40 & 36 & 15000000 \\
\hline 35 & 12 & 1000000 & 30 & 24 & 70000 & 30 & 12 & 700000 \\
\hline 35 & 60 & 290000000 & 30 & 72 & 2300000000 & 30 & 60 & 360000000 \\
\hline 35 & 36 & 6000000 & 30 & 48 & 300000000 & 30 & 36 & 17000000 \\
\hline 35 & 36 & 6000000 & 30 & 48 & 480000000 & 30 & 36 & 30000000 \\
\hline
\end{tabular}

T: Temperatura.

t: Tiempo. 


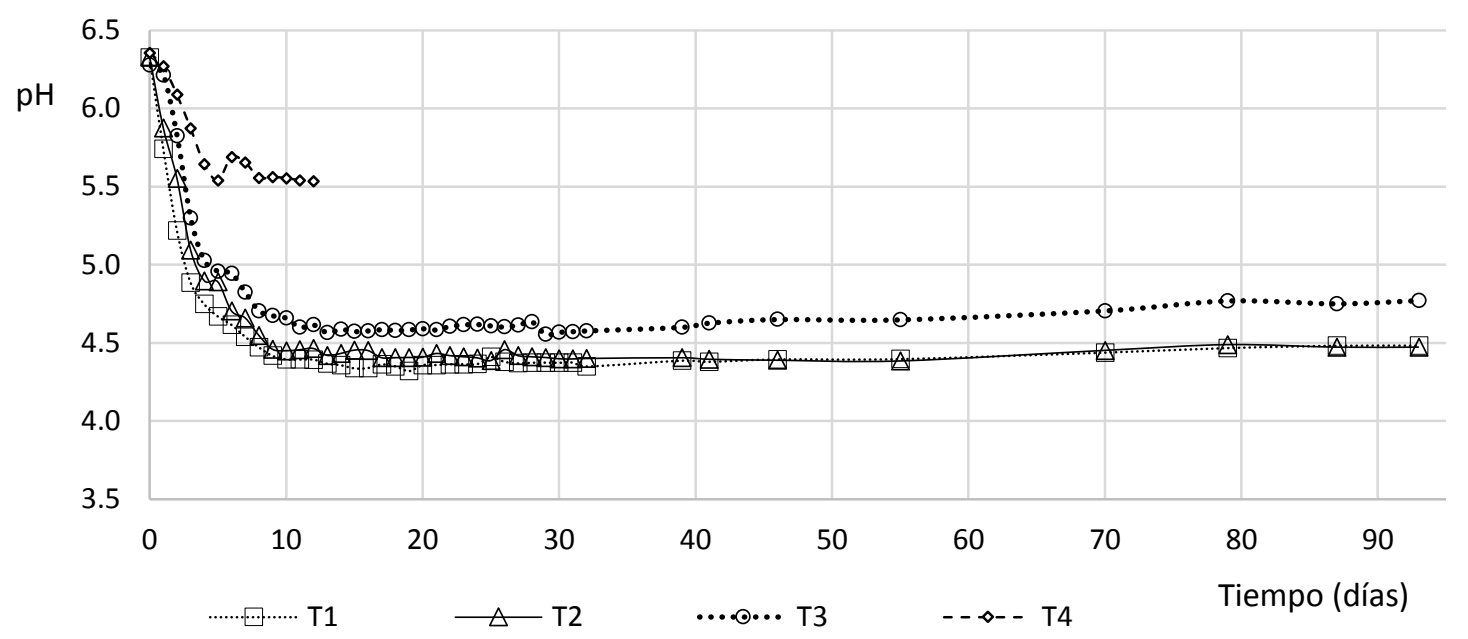

Figura 2. Valores de $\mathrm{pH}$ de los ensilados $\mathrm{T} 1, \mathrm{~T} 2$, $\mathrm{T} 3$ y $\mathrm{T} 4$.

Análisis microbiológicos

El conteo de UFC/g de hongos del tratamiento T2, a los 90 días de almacenamiento fue de $100 \mathrm{UFC/g}$, en el estudio se percibió olor a alcohol en el ensilado, atribuyéndose a las levaduras $\left(1.7 \times 10^{4}\right.$ a $4.8 \times 10^{6}$ UFC/g) esa característica.

El conteo de aerobios mesófilos en la melaza fue de $1.3 \times 10^{4} \mathrm{UFC} / \mathrm{g}$ y en el residuo crudo de trucha fue de $7.2 \times 10^{5} \mathrm{UFC} / \mathrm{g}$, esa carga microbiana disminuyó en el proceso de ensilado (T2), llegando a valores de $1.1 \times 10^{4}$ UFC/g a los 90 días de almacenamiento, debido probablemente al bajo $\mathrm{pH}$ del ensilado que impide el crecimiento de las bacterias.

Análisis químicos

Los residuos de trucha presentaron: $67.2 \%$ de humedad, $12.6 \%$ de proteína cruda, $17.9 \%$ de grasa cruda y $2.4 \%$ de cenizas, valores diferentes a los obtenidos por Berenz et al. (1994), quienes elaboraron un ensilado con residuos cocidos de sardina $(65.8 \% \pm$ 1.1 de humedad; $16.2 \% \pm 0.15$ de proteína; $8.4 \% \pm 1.3$ de grasa y $7.24 \% \pm 0.4$ de cenizas y carbohidratos de $2.6 \% \pm 1.2)$

El ensilado de residuo de trucha presentó contenidos de humedad de $54.5 \% \pm 4.0$; proteína $8.2 \%$ \pm 0.14 , grasa $29.6 \% \pm 6.3$ y cenizas $1.85 \% \pm 0.5$, con un contenido aproximado de carbohidratos de $6 \%$, valores diferentes a los encontrados por Albrecht \& Salas (2013) para ensilado de residuos crudos de anchoveta (humedad 69.5\% \pm 1.2 ; proteína $13.8 \% \pm$ 0.7 , grasa $6.0 \% \pm 1.1$ y cenizas $4.7 \% \pm 0.6$ ), el contenido de grasa de los residuos y ensilado de trucha de este trabajo fueron mayores que los mencionados por otros autores que usaron residuos de pescado de origen marino.

\section{El potencial de hidrógeno $(\mathrm{pH})$}

Los valores de $\mathrm{pH}$ de los residuos de trucha y al iniciar el proceso de ensilado fueron $6.1 \pm 0.1$ y $6.4 \pm$
0.1, respectivamente. Albrecht \& Salas (2013) iniciaron el proceso de ensilado con $\mathrm{pH} 6.47$.

A los 5 días de iniciado el proceso de ensilado, el $\mathrm{pH}$ del tratamiento T4 fue de 5.5, y nunca disminuyó, siendo probable que las bacterias de descomposición hayan proliferado generando aminas y aumentando el $\mathrm{pH}$ del ensilado, siendo descartado este tratamiento.

El T3 mantuvo valores de $\mathrm{pH}$ cercanos a 4.6, pero no llegó a 4.5 (Figura 2). Su formulación contenía menor cantidad de melaza, equivalente al $7 \%$ de los residuos, en comparación con los demás tratamientos (15\% de los residuos), es probable que haya sido insuficiente la cantidad de melaza para que A. oryzae pueda generar mayor cantidad de ácido. Vásquez et al. (2011) elaboraron un ensilado biológico con elevado porcentaje de glucosa, a nivel de laboratorio, a partir de residuos viscerales (estómago e intestinos) de pez espada, raya y tiburón, a $25^{\circ} \mathrm{C}$ con $25 \mathrm{~g}$ de residuos triturados, $8 \mathrm{~mL}$ de glucosa (equivalente a $32 \%$ de los residuos) y $2 \mathrm{ml}$ del inóculo de bacterias lácticas, logrando ensilados con valores de $\mathrm{pH}<4.5$.

Los tratamientos $\mathrm{T} 1$ y $\mathrm{T} 2$, alcanzaron un $\mathrm{pH} \leq 4.5 \mathrm{a}$ los 9 días de iniciado el proceso de ensilado y mantuvieron ese $\mathrm{pH}$ a temperatura ambiente, hasta los 90 días que duró el presente estudio, similares resultados fueron obtenidos por Albrecht \& Salas (2013) en ensilados elaborados con residuos crudos de anchoveta, melaza y cepas de $A$. oryzae con incubación durante 4 días a $40{ }^{\circ} \mathrm{C}$.

Es importante mencionar que el $\mathrm{pH}$ fue el mejor indicador del proceso de ensilado, valores de $\mathrm{pH} \leq 4.5$ disminuyen la probabilidad de deterioro de los residuos de trucha y aseguran la estabilidad del ensilado en almacenamiento.

$\underline{\text { Valores de acidez }}$

Los valores de acidez de los tratamientos de ensilado fueron fluctuantes (Figura 3), el valor de la acidez no es un buen indicador para evaluar el proceso de ensilado, al tener un comportamiento errático. 


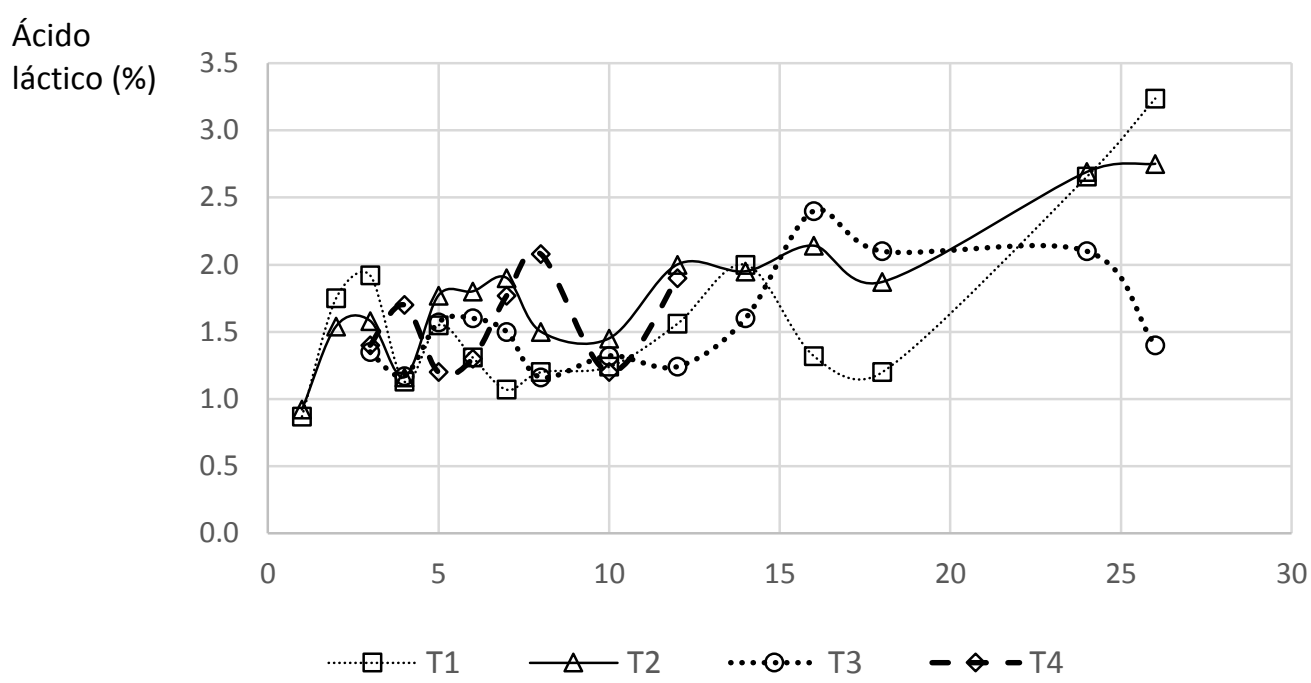

Figura 3. Valores de acidez expresado en porcentaje de ácido láctico (g/100 g de ensilado).

Al respecto, Figueroa \& Sánchez (1997) mencionan que de acuerdo a los resultados de los estudios realizados del proceso del ensilado, pareciera que dicho proceso se puede dividir en dos fases distintas y se complementan: una correspondiente a la hidrólisis o licuefacción, la cual está gobernada por las enzimas proteolíticas, y la otra correspondiente a la acidificación y reducción del pH, la cual está gobernada por la acción de los microorganismos ácido-lácticos.

Asimismo, mencionan que existe un sistema de auto control, cuando se generan bases volátiles o compuestos nitrogenados que incrementen el $\mathrm{pH}$, se inicia la producción de ácido por parte de los microorganismos, hasta que la cantidad de ácido en el medio sea suficiente para reducir el $\mathrm{pH}$ a niveles cercanos a 4, y detener o controlar el crecimiento de las bacterias y por ende la producción de ácido.

A medida que la hidrólisis protéica progresa, se producen compuestos nitrogenados, como péptidos, aminoácidos, aminas, amonio y otros compuestos de bajo peso molecular, los cuales perturban la capacidad amortiguadora del producto, incrementándose los valores de $\mathrm{pH}$, lo cual conduce a que las bacterias ácido-lácticas comiencen a producir ácido y reducir nuevamente el pH a su valor inicial (Lindgren \& Pleaje, 1983).

Histamina

La histamina es producida a partir de la descarboxilación de la histidina por las bacterias del deterioro, las cuales son activas en respuesta al $\mathrm{pH}$ ácido, presumiblemente para elevar el $\mathrm{pH}$ del medio de crecimiento a través de la producción de aminas (histamina) (Huss, 1988). Otra posibilidad de formación de histamina puede ser la descarboxilación de la "histidina proteica" generada durante la hidrolisis proteica en el proceso de ensilado por acción de las enzimas del $A$. oryzae.
En el presente trabajo los valores de histamina (Tabla 5) de los tratamientos T1 y T2 fueron menores que el nivel permitido para consumo humano $(<200 \mathrm{mg}$ histamina/kg de pescado).

Por otro lado, no existió un efecto combinado de los tratamientos y tiempo de almacenamiento sobre los valores de histamina ( $>>0.05)$, pero si hubo un efecto de los tratamientos en la formación de histamina $(\mathrm{p}<0.05)$, el tratamiento T2 presentó los menores valores de histamina durante el periodo evaluado (Tabla 5), se recomienda esta formulación para la elaboración de ensilado y su posterior destino para alimento de animales.

El tratamiento T3 presentó los mayores valores de histamina y diferencia significativa $(\mathrm{p}<0.05)$ con los ensilados T1 y T2 (Tabla 5). Los valores de histamina de este trabajo fueron inferiores a los encontrados por Albrecht \& Salas (2013) quienes encontraron 549 y 708 $\mathrm{mg}$ de histamina/kg de ensilado de residuos de anchoveta a los 15 días y 90 días respectivamente, almacenados al ambiente $\left(20\right.$ a $\left.30{ }^{\circ} \mathrm{C}\right)$.

Tabla 5. Valores de histamina $(\mathrm{mg} / \mathrm{kg})$ de los ensilados T1, T2 y T3 durante los 25, 52 y 90 días de almacenamiento $\left(2 \mathrm{a} 15^{\circ} \mathrm{C}\right)$.

\begin{tabular}{|c|c|c|c|}
\hline \multirow{2}{*}{ 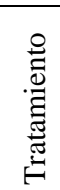 } & \multicolumn{3}{|c|}{ Tiempo (días) } \\
\hline & 25 & 52 & 90 \\
\hline T1 & $88.7^{\mathrm{a}} \pm 4.2$ & $136.6^{\mathrm{a}} \pm 12.8$ & $140.1^{\mathrm{ab}} \pm 18.2$ \\
\hline $\mathrm{T} 2$ & $63.1^{\mathrm{a}} \pm 2.0$ & $80.8^{a} \pm 15.9$ & $83.7^{\mathrm{a}} \pm 20.4$ \\
\hline T 3 & $206.0^{\mathrm{b}} \pm 84.9$ & $239.2^{\mathrm{b}} \pm 75.2$ & $236.0^{\mathrm{b}} \pm 82.3$ \\
\hline
\end{tabular}




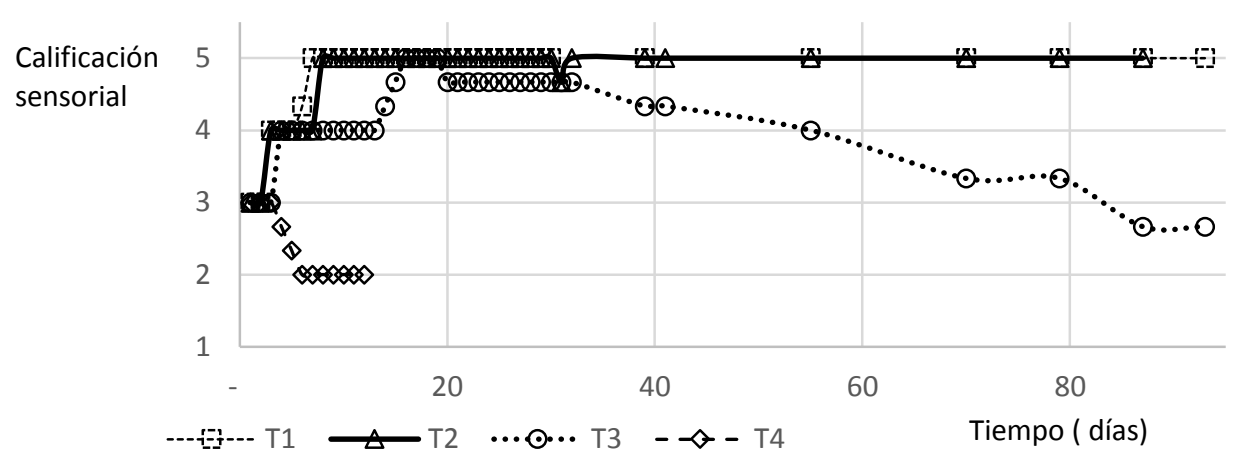

Figura 4. Calificación del olor de los tratamientos de ensilados T1, T2, T3 y T4 durante 90 días.

\section{Análisis sensorial}

El olor y el $\mathrm{pH}$ fueron las variables que indicaron el buen o mal desarrollo del proceso de ensilado, presentaron relación inversamente proporcional a los valores de $\mathrm{pH}$, a menores valores de $\mathrm{pH}$ mayor puntaje en el olor. En el segundo día de la preparación de ensilado se percibió una mezcla de olores de pescado y melaza, posteriormente se incrementó el olor a frutas (poco fermentada) de los tratamientos $\mathrm{T} 1$ y $\mathrm{T} 2$, manteniendo la mayor calificación hasta el término del estudio (90 días). Los tratamientos T3 y T4 llegaron hasta la descomposición (Figura 4).

El ensilado puede ser usado como insumo en la dieta de crecimiento-engorde de cerdos y para el engorde de ovejas (Calderón-Quispe et al., 2017; Parisuaña-Callata et al., 2018).

\section{Conclusiones}

El pH y el olor fueron los parámetros que permitieron evaluar el proceso del ensilado.

El koji es un insumo que permite la elaboración de ensilados con residuos crudos de trucha al ambiente en Iscayapi (Arapa/Puno).

La formulación con: 'residuo crudo de trucha' : 'melaza' : 'koji de arroz', de $10: 1.5: 1$, fue la mejor para la elaboración del ensilado crudo de trucha.

La obtención de ensilado, es una tecnología barata, versátil, con un requerimiento energético mínimo, la cual puede aplicarse a nivel artesanal e industrial.

El proceso de ensilado puede ser un medio para generar ingresos económicos de los residuos que son desechados.

El proceso de ensilaje, preserva la proteína animal obteniéndose un producto estable al medio ambiente hasta 6 meses.

\section{Agradecimientos}

Se agradece a Innóvate Perú por el financiamiento del Proyecto PIPEI-6-P-024-005-13, a la empresa ARAPA San Pedro y San Pablo S.A.C. y al Instituto Tecnológico de la Producción. Se agradece a la Blga. Katherine Díaz por la realización de los análisis microbiológicos.

\section{Literatura citada}

Albrecht M. \& Salas A. 2013. Escalamiento en la preparación de ensilaje crudo de pescado mediante la adición de koji y melaza. Bol. Invest. Inst. Tecnol. Prod. Perú, 11: 11-15.

Albrecht M. \& Torpoco M. 2008. Obtención de residuos crudos de pescado fermentados y proteolisados (ensilados) mediante el uso de "koji". Bol. Invest. Inst. tecnol. Prod. Perú, 8: 9-16.

AOAC (Association of Official Analytical Chemists). 2005. Acidity of milk titrimetric method. 947.05.

Areche N. \& Berenz Z. 1990. Inocuidad del ensilado de pescado en la producción del vómito negro. Bol. Inv. Ins. Tec. Pes., 3(1): 37-42.

Bechman A., Phillips R. \& Chen J. 2012. Changes in select physical property and enzyme activity of rice and barley koji during fermentation and storage. J. Food Sci. 77(6): M318-M322. DOI: https://doi.org/10.1111/j.17503841.2012.02691.x.

Berenz Z., Romero F. \& Beoutis G. 1994. Utilización del ensilado de residuos de pescado en dietas para pollos de carne. Bol. Inv.Ins.Tec.Pes. 4(1): 91-104.

Calderón-Quispe V., Churacutipa-Mamani M., Salas A., Barriga-Sánchez M. \& Araníbar M. 2017. Inclusión de Ensilado de Residuos de Trucha en el Alimento de Cerdos y su Efecto en el Rendimiento Productivo y Sabor de la Carne. Revista De Investigaciones Veterinarias Del Perú, 28(2): 265-274. DOI: https://doi.org/10.15381/rivep.v28i2.13055.

FAO (Food and Agriculture Organization). 1986. Food and Nutrition Papers 14/7 Manuals of Food Quality Control.

FDA (Food and Drug Administration). 2001. Enumeration of yeast and Mold in Food. Dilution Plating Technique. Bacteriological Analytical Manual on Line. January 2001. 8th Edition, Chapter 18, 1995.

Figueroa V. \& Sánchez M. 1997. Tratamiento y utilización de residuos de origen animal, pesquero y alimenticio en la alimentación animal. Estudio FAO Producción y sanidad animal 134. Memorias de un taller regional organizado por el Instituto de Investigaciones porcinas (IIP) y la FAO, en la Habana, Cuba del 5 al 8 de setiembre de 1994.

Herrampf J. \& Piedad-Pascual F. 2000. Fish and Other marine silage. In: Handbook on ingredients for Aquaculture Feeds. pp 198- 210. Editorial Springer.

Huss H. 1988. Fresh fish-quality and quality changes. A training manual prepares for FAO/DANIDA Training Programme on Fish Technology and Quality Control. 
Kikko P.H.E. 2015. Ficha técnica de koji. Comunicación personal.

Lindgren S. \& Pleaje M. 1983. Silage fermentation of fish or fish waste products with lactic acid bacteria. Journal of the Science of Food and Agriculture, 34(10): 1057-1067. DOI: https://doi.org/10.1002/jsfa.2740341005.

Instituto Nacional de Normalización - Chile. 2001. Norma Chilena 2637. Of. 2001. NCh2637.Of2001. Productos hidrobiológicos - Determinación de histamina y otras aminas biogénicas. Método HPLC con detector UV.

Ministerio de la Producción - Perú. 2015. Anuario Estadístico Pesquero y Acuícola http://www.produce.gob.pe/documentos/estadisticas/anu arios/anuario-estadistico-pesca-2015.pdf.
Minitab. 2007. Meet Minitab 15 for Windows ${ }^{\mathrm{R}}$. https://www.addlink.es/images/pdf/agdweb1513.pdf.

Parisuaña-Callata J, Churacutipa-Mamani M., Salas A., Barriga-Sánchez M. \& Araníbar M. 2018. Ensilado de residuos de trucha en la alimentación de ovinos de engorde. Rev Inv. Vet. Perú, 29(1): 151-160.

Vásquez J., Nogueira M., Duran A., Prieto M., RodríguezAmado I., Rial D., Gonzales M. \& Murado M. 2011. Preparation of marine silage of swordfish, ray and shark visceral waste by lactic acid bacteria. Journal of Food engineering 103: 442-448.

\footnotetext{
${ }^{1}$ Dirección de Investigación y Desarrollo, Innovación y Transferencia Tecnológica. Instituto Tecnológico de la Producción. Carretera Ventanilla km 5.2, Callao. mbarriga@itp.gob.pe.

${ }^{2}$ ARAPA San Pedro y San Pablo S.A.C. Comunidad Campesina Iscayapi Km 04 Carretera Arapa-Chupa, Puno. marisol.churacutipa@gmail.com.

${ }^{3}$ Cite-Pesquero. Instituto Tecnológico de la Producción. Carretera Ventanilla km 5.2, Callao. asalas@itp.gob.pe.
} 